\title{
A CRISE POLÍTICA E ECONÔMICA NO BRASIL: \\ Uma análise de conjuntura sob a ótica da opinião pública no Chile, Bolívia, Peru e Equador
}

\author{
Pedro Bedim ${ }^{1}$
}

\begin{abstract}
Resumo
Esta análise de conjuntura oferece um retrato retrospectivo da crise política e econômica enfrentada pelo governo brasileiro no mês de abertura do processo de impeachment contra a presidente Dilma Rousseff em abril de 2015, tal como avaliado sob a ótica da opinião pública no Chile, Bolívia, Peru e Equador.

Palavras-chave: Impeachment - Crise - Brasil - Bolívia - Chile - Equador - Peru
\end{abstract}

\section{Introdução}

A crise política brasileira é causada por uma combinação de fatores, como a operação Lava Jato, que vem descobrindo uma rede vasta e antiga de corrupção em diversos níveis da administração pública e na iniciativa privada, tendo no seu centro a gigante petrolífera Petrobras. Outro componente que perpetua a crise política é o conflito de interesses entre os principais membros do executivo, legislativo e judiciário. Além disso, o processo de Impeachment da presidente Dilma se põe como peça-chave na crise política existente atualmente no Brasil. Aceito pelo presidente da Câmara, Eduardo Cunha, no dia 02 de dezembro de 2015 e que foi votado em plenário no dia 17 de abril de 2016, sendo então aprovado pelos deputados federais.

Uma análise de como os países vizinhos enxergaram e retrataram o cenário no mês de abril - o mês da votação do Impeachment na Câmara - se faz necessária, por causa da vasta influência da política economia brasileira sobre esses países. Sendo assim, aqui será feita uma análise das reações e reverberações de Chile, Bolívia, Peru e Equador - países importantes da região que não fazem parte do MERCOSUL. Esses países foram selecionados através de sorteio entre os outros membros do PET. Essa

\footnotetext{
${ }^{1}$ Aluno da graduação de Relações Internacionais pela Pontifícia Universidade Católica do Rio de Janeiro (PUC-Rio).
} 
análise terá como fontes principais os jornais mais lidos dos países em questão e também estará alerta para transbordamentos do desenrolar da crise econômica e da operação Lava Jato. Além disso, podemos usar essa análise que foca apenas no mês de abril para compará-lo com outros períodos e episódios na crise política e econômica brasileira.

\section{Atores e Interesses}

Peru

O presidente do Peru era o líder do partido nacionalista Ollanta Humala. A nação encontrava-se no meio de eleições gerais rumando para o segundo turno, com pesquisas dando a liderança para Keiko Fujimori, filha do ex-presidente Alberto Fujimori que hoje está preso. Não se sabia ainda quem iria para o segundo turno com Keiko, mas o favorito era Pedro Pablo Kuczynski, candidato de centro-direita e exministro.

O cenário político peruano também foi afetado pela operação Lava Jato. Foi instalada uma comissão no congresso peruano para investigar a relação do Estado Peruano com as descobertas da operação Lava Jato. Até abril, essa comissão já levantou o sigilo bancário de 432 investigados, entre pessoas jurídicas e físicas. Entre esses investigados, alguns nomes expressivos como a primeira dama, Nadine Heredia e os expresidentes, Alan García e Alejandro Toledo e o ex-primeiro-ministro Pedro Pablo Kuczynski ${ }^{2}$.

A primeira dama e líder do Partido Nacionalista do Peru, Nadine Heredia, fora acusada de ter recebido dinheiro de empreiteiras brasileiras envolvidas na operação Lava Jato. No final de março, Heredia depôs diante de uma comissão do Congresso que investiga o suposto pagamento de subornos de empreiteiras do Brasil para obter obras no Peru. Além disso, ela também foi questionada sobre a campanha eleitoral de 2011, quando teria recebido contribuições de empreiteiras brasileiras em troca de obras no

\footnotetext{
${ }^{2}$ EL COMERCIO. Nadine: No recibí “coimas ni sobornos de empresas brasileñas. Disponível em: http://elcomercio.pe/politica/congreso/nadine-heredia-ira-hoy-comision-lava-jato-confirma-roy-gatesnoticia-1890724 Acesso em: 25 de abr. de 2016.
} 
futuro governo. Ela afirma que de fato ocorreram reuniões com empresários de várias nacionalidades, inclusive peruanos, mas defende que isso não significa a existência de subornos ou qualquer compromisso com projetos ou obras ${ }^{3}$. Essa pode ser a causa para que Ollanta tenha sido o único chefe de Estado presente nessa pesquisa que não se pronunciou de forma contundente a favor ou contra o impeachment.

Ao focarmos mais diretamente em como o quadro brasileiro tem sido avaliado no Peru podemos ver o seguinte. Enquanto o jornal El Comercio focou no transbordamento da operação Lava Jato na política Peruana, o jornal Diario Correo noticiou mais o processo de impeachment e os pronunciamentos de Dilma Rousseff ao se defender. Foram noticiadas as acusações da presidenta de que o processo de impeachment possuir um componente forte de machismo ${ }^{4}$. Também foi destaque quando Rousseff se disse indignada com o processo de impeachment, qualificando-o como um golpe de Estado ${ }^{5}$. No dia 17/04, o jornal notificou a aprovação do impeachment pela Câmara dos Deputados lembrando-se das acusações por corrupção contra Michel Temer e Eduardo Cunha ${ }^{6}$. O jornal também publicou uma coluna que coloca o afastamento da presidenta brasileira como um golpe de estado moderno, sem tanques e sem armas, mas camuflado como um processo legal ${ }^{7}$.

Podemos entender a magnitude do impacto que a política brasileira gera nos países vizinhos ao vermos grandes figuras do cenário político peruano sendo investigadas a partir do transbordamento de investigações brasileiras. A partir dos desdobramentos da CPI no Peru, podemos ver a grande influência de certas empresas brasileiras nesses países vizinhos. Esses dois componentes denotam o gigantesco peso dos rumos da política e da economia brasileira na política e na economia das nações

\footnotetext{
${ }^{3}$ Ibiden.

${ }^{4}$ DIARIO CORREO. Dilma Rousseff afirma que proceso em su contra tiene "compnente fuerte" de machismo. Disponível em: http://diariocorreo.pe/mundo/dilma-rousseff-dice-que-proceso-en-su-contratiene-componente-fuerte-de-machismo-667368/ Acesso em: 25 de abr. de 2016.

5 DIARIO CORREO. Dilma Rousseff sobre votación del 'impeachment': Me siento indignada". Disponível em: http://diariocorreo.pe/mundo/dilma-rousseff-sobre-votacion-del-impeachment-mesiento-indignada-667181/Acesso em: 25 de abr. de 2016.

${ }^{6}$ DIARIO CORREO. Brasil: diputados aprobaron impeachment contra Dilma Rousseff. Disponível em: http://diariocorreo.pe/mundo/brasil-diputados-aprobaron-impeachment-contra-dilma-rousseff-667039/ Acesso em: 25 de abr. de 2016.

7 DIARIO CORREO. Dilma Rousseff y um "golpe moderno". Disponível em: http://diariocorreo.pe/mundo/dilma-rousseff-y-un-golpe-moderno-667929/Acesso em: 25 de abr. de 2016.
} 
vizinhas. Fator esse que será observado também nos outros países presentes nessa análise.

\section{Chile}

Para analisarmos o caso do Chile é importante entendermos a situação de sua presidente. Em 2013, Michelle Bachelet Jeria, do partido Socialista, foi eleita para o seu segundo mandato como presidenta, já tendo sido eleita em 2006, sendo a primeira e única presidenta mulher do Chile. Com a saída da Cristina Fernandez de Kirchner da presidência da Argentina, agora sobraram apenas Bachelet e Dilma como as únicas presidentes mulheres do continente sul-americano. Assim como Dilma, Bachelet também sofria com baixíssimos índices de aprovação. Por essa situação similar, por afinidade política e até mesmo por sororidade, a presidente do Chile vocalizava abertamente o seu apoio à Dilma, principalmente no corte temporal aqui analisado, com aproximação do impeachment. No início de abril, Bachelet disse em entrevista à CNN Chile que Dilma Rousseff é uma mulher séria, honesta e responsável, confirmando a estreita relação entre as duas ${ }^{8}$.

Algumas tendências sobre a percepção chilena da situação do Brasil foram vistas nas notícias e colunas de dois dos maiores jornais Chilenos, o 24 Horas e o La Nación. Foi observada uma desconfiança sobre o vice-presidente brasileiro Michel Temer, principalmente após o vazamento do áudio em que ele apresenta suas propostas para um eventual mandato, esse vazamento foi entendido como intencional e estratégico. Vemos também que os líderes da oposição não são citados em manchetes. Ao reportarem a crise política brasileira, os jornais Chilenos enfatizavam as falas de juízes do Supremo Tribunal Federal, da própria presidenta Dilma Rousseff e do ex-presidente Luiz Inácio Lula da Silva. O próprio Michel Temer só foi mencionado como objeto de análise ou no momento em que Rousseff o classificou como "traidor e golpista", o que foi descrito como um endurecimento no discurso não visto antes.

\footnotetext{
${ }^{8}$ LA NACION. Bachelet: Dilma Rousseff es uma 'mujer honesta y responsable. Disponível em: http://www.lanacion.cl/noticias/pais/politica/bachelet-dilma-rousseff-es-una-mujer-honesta-yresponsable/2016-04-06/165342.html Acesso em: 25 de abr. de 2016.
} 
Durante a votação e aprovação do impeachment e a última quinzena de abril, o jornal 24 Horas destacou quase os mesmos pontos explorados nos jornais peruanos. $\mathrm{O}$ jornal reportou as acusações de Dilma Rousseff de que o processo de impeachment contra ela possui um forte componente machista ${ }^{9}$. O jornal reportou, ainda, a caracterização feita da presidenta do impeachment como um golpe de Estado não tradicional $^{10}$.

Em paralelo, o jornal La Nación explorou os discursos proferidos pelos deputados na seção de votação sobre o impeachment, destacando a religiosidade dos mesmos $^{11}$. Ainda sobre os discursos, o La Nación foi o único jornal Chileno aqui pesquisado a chamar atenção para as manifestações pela cassação do mandato do deputado Jair Bolsonaro por ter homenageado um notório torturador da Ditadura Militar, ao anunciar o seu voto a favor do impeachment ${ }^{12}$. Além de também divulgar o argumento da presidente de que o impeachment seria um golpe disfarçado de processo legal, o jornal divulgou a fala de Dilma ao dizer que se sentia triste com o resultado na Câmara, porém ainda disposta a lutar contra esse golpe. Finalmente, o La Nación reportou o quarto testemunho de que Eduardo Cunha teria recebido subornos, feito por Fernando Soares. Na mesma reportagem, o jornal destacou que Cunha é o segundo na linha sucessória da presidência ${ }^{13}$. Aqui vemos como que os jornais tendem a citar as palavras da presidente Dilma, enquanto que outros agentes políticos tendem a serem noticiados na terceira pessoa.

\footnotetext{
924 HORAS. Rousseff considera que está siendo víctima de um trato injusto em parte por ser mujer. Disponível em: http://www.24horas.cl/internacional/rousseff-considera-que-esta-siendo-victima-de-untrato-injusto-en-parte-por-ser-mujer-1991218 Acesso em: 19 de abr. de 2016.

${ }^{10} 24$ HORAS. Dilma Rousseff tras aprobación de impeachment: "Es um golpe de Estado no tradicional". Disponível em: http://www.24horas.cl/internacional/dilma-rousseff-tras-aprobacion-de-impeachment-esun-golpe-de-estado-no-tradicional-1990347 Acesso em: 25 de abr. de 2016.

${ }^{11}$ LA NACION. 'Em nombre de dios y del pueblo brasilño' inicia a sesión que decide impeachment contra Rousseff. Disponível em: http://www.lanacion.cl/noticias/mundo/brasil/en-nombre-de-dios-y-delpueblo-brasileno-inicia-sesion-que-decide/2016-04-17/163633.html Acesso em: 25 de abr. de 2016.

12 LA NACION. Brasil: piden sancionar al polémico diputado fan de um torturador. Disponível em: http://www.lanacion.cl/noticias/videos/mundo/brasil-piden-sancionar-al-polemico-diputado-fan-de-untorturador/2016-04-21/120238.html Acesso em: 25 de abr. de 2016.

${ }^{13}$ LA NACION. Rousseff se dice 'triste' pero dispuesta a defender su mandato de 'um golpe'. Disponível em: http://www.lanacion.cl/noticias/rousseff-se-dice-triste-pero-dispuesta-a-defender-su-mandato-deun/2016-04-18/203936.html Acesso em: 25 de abr. de 2016.
} 
Vale a pena atentar que houve um maior destaque para as manifestações contra o impeachment do que para as a favor dele, apesar das manifestações favoráveis ao impeachment terem sido maiores. Juntamente a isso, muitos artigos indagaram quais seriam as reais acusações que estão sendo feitas contra Dilma Rousseff. Esses artigos também questionaram o porquê de as acusações do impeachment não estarem baseadas na operação Lava Jato, nem nas denúncias de dinheiro ilícito para a campanha de 2014, mas sim nas "pedaladas fiscais". Os artigos de opinião também exploraram o atual debate sobre se as pedaladas fiscais seriam de fato crime de responsabilidade.

\section{Bolívia}

Evo Morales tem sido um dos principais apoiadores internacionais do mandato da presidenta Dilma. No dia 19 de março, na cúpula da Unasul, Morales pediu ao presidente do Uruguai, Tabaré Vásquez, que exerce a presidência temporária da Unasul, que fosse convocada uma cúpula de emergência no Brasil, para defender a presidente Dilma Rousseff. Evo também afirmou que a direita brasileira quer tomar o poder através de um golpe e frustrar uma possível volta de Lula à presidência ${ }^{14}$.

Ao focarmos mais na visão da mídia sobre a crise econômica e política brasileira vimos o seguinte. O jornal El Tiempo reportou as falas de Dilma Rousseff com bastante veemência. Principalmente no momento em que ela nomeou Temer como traidor e quando afirma não ter intenções de renunciar à presidência ${ }^{15}$. Apesar de exibir uma posição majoritariamente a favor do governo Dilma Rousseff, o El Tiempo também reportou as manifestações em comemoração à aceitação do processo de impeachment pela comissão da Câmara. Além disso, o jornal também reportou algumas falas de líderes da oposição.

Após a aprovação do impeachment na Câmara, o jornal El Tiempo publicou um editorial, no qual diz não ver uma recuperação para a crise política e econômica do

\footnotetext{
${ }^{14}$ LA TERCERA. Evo Morales pide cumbre de Unasur em Brasil para defender a Dilma y Lula. Disponível em: http://www.latercera.com/noticia/mundo/2016/03/678-672974-9-evo-morales-pidecumbre-de-unasur-en-brasil-para-defender-a-dilma-y-lula.shtml Acesso em: 25 de abr. de 2016.

15 EL TIEMPO. Dilma Rousseff acusa a su vicepresidente de 'traidor'. Disponível em: http://www.eltiempo.com/mundo/latinoamerica/declaraciones-de-dilma-de-michel-temer/16562085 Acesso em: 25 de abr. de 2016.
} 
Brasil vindo das mãos de Dilma nem de seus opositores e sucessores e destaca o crescente pleito popular por novas eleições. O editorial mudou de tom ao comentar sobre as acusações contra o ex-presidente Lula, ao dizer que ele foi um caso de extremo sucesso na América Latina e que agora luta com garras e dentes para manter o seu legado $^{16}$. Nas colunas publicadas no jornal são explorados temas como o fim de uma promessa petista, com o desmantelamento do legado de Dilma e Lula. A corrupção envolvendo os sucessores da presidenta, os gestos dos possíveis sucessores sendo vistos como golpe de Estado por alguns colunistas e o pleito por eleições imediatas ${ }^{17}$. Também foi destacada em uma coluna a honestidade material de Rousseff, e sustentado o argumento de que se ela cair será por suas qualidades pessoais de pouco diálogo e negociação ${ }^{18}$.

Por sua vez, o jornal El Espectador publicou uma onda de artigos de opinião sobre a crise política brasileira. Nesses artigos vemos o enaltecimento do passado de guerrilheira da presidenta Dilma, mas também é explorada a decepção perante o seu governo, principalmente sobre os casos de corrupção ${ }^{19}$. Também foi enfatizado que Dilma Rousseff ainda não é acusada por enriquecimento ilícito, diferente de muitos de seus opositores e aliados. Nos artigos de opinião o poder Legislativo foi constantemente apontado como muito corrupto, com destaque ao presidente da Câmara, Eduardo Cunha, como peça chave da crise política. Também foram enfatizadas as antigas acusações na justiça contra Cunha e a sua condição de réu no Supremo Tribunal Federal. Os artigos discutiram também as acusações sofridas por Michel Temer e pelo presidente do Senado, Renan Calheiros ${ }^{20}$.

16 EL TIEMPO. Editorial: La sinsalida brasileña. Disponível em: http://www.eltiempo.com/mundo/latinoamerica/la-sinsalida-brasilena-editorial-el-tiempo-20-de-abril-de2016/16568531Acesso em: 25 de abr. de 2016.

${ }^{17}$ EL TIEMPO. Golpe en Brasil. Disponível em: http:/www.eltiempo.com/opinion/columnistas/golpeen-brasil-julio-gomes-dos-santos-columnista-el-tiempo/16571524 Acesso em: 25 de abr. de 2016.

18 EL TIEMPO. La conspiración contra Dilma. Disponível em: http://www.eltiempo.com/opinion/columnistas/la-conspiracion-contra-dilma-sergio-munoz-bata-columnael-tiempo/16573038 Acesso em: 26 de abr. de 2016.

1919 EL ESPECTADOR. Dilma. Disponível em: http://www.elespectador.com/opinion/dilma-0 Acesso em: 25 de abr. de 2016.

20 EL ESPECTADOR. Brasil: Quién está libre de culpas? Disponível em: http://www.elespectador.com/noticias/elmundo/brasil-quien-esta-libre-de-culpas-articulo-627299 Acesso em: 25 de abr. de 2016. 
Após o processo de impeachment ser aprovado pela Câmara, o El Espectador foi mais veemente em seus artigos publicados. Um artigo de opinião mostrou horror com os discursos dos deputados na votação do impeachment, considerando o impeachment de Dilma antiético pela forma como está sendo conduzido e argumentando que foi culpa da esquerda, por ter adotado o manual da direita ao tentar justificar a corrupção. Finalmente, apontando para um possível fim da Operação Lava Jato num possível governo Michel Temer ${ }^{21}$. Também foi enfatizado o caráter político da destituição de Dilma, em detrimento do argumento de que seria um processo pela luta anticorrupção ${ }^{22}$. Finalmente, foi explorada por um artigo a perda de espaço do Brasil nas projeções do futuro cenário internacional ${ }^{23}$.

\section{Equador}

No caso do Equador, foram pesquisados os jornais El Universo e El Comercio. O jornal El Universo publicou um artigo expressando sua posição de que não há um golpe em curso no Brasil, tampando o argumento do golpe como pura retórica do Partido dos Trabalhadores. O mesmo artigo argumenta que Dilma e Lula defenderam o impeachment do ex-presidente Fernando Collor de Mello e que pediram a renúncia e o início do processo de impeachment do ex-presidente Fernando Henrique Cardoso, sem considerarem nenhuma dessas ações como golpistas. O jornal também considera o impeachment como tendo dois componentes, o jurídico e o político. Para o El Universo, Rousseff teria cometido crime de responsabilidade ao ter praticado as chamadas pedaladas fiscais, considerando esse um argumento jurídico sólido para a derrubada da presidenta $^{24}$.

21 EL ESPECTADOR. Brasil, em el limbo. Disponível em: http://www.elespectador.com/opinion/editorial/brasil-el-limbo-articulo-627994 Acesso em: 25 de abr. de 2016.

${ }^{22}$ EL ESPECTADOR. Dilma Rousseff y la situación en Brasil: cuál democracia? Disponível em: http://www.elespectador.com/noticias/elmundo/dilma-rousseff-y-situacion-brasil-cual-democracia-

articulo-627763 Acesso em: 25 de abr. de 2016.
23 EL ESPECTADOR. Brasi, de la fama al olvido. Disponível em: http://www.elespectador.com/opinion/brasil-de-fama-al-olvido Acesso em: 25 de abr. de 2016.

24 EL UNIVERSO. Debate sobre el supuesto 'golpe' contra Rousseff. Disponível em: http://www.eluniverso.com/noticias/2016/04/01/nota/5496201/debate-sobre-supuesto-golpe-contrarousseff Acesso em: 25 de abr. de 2016. 
O Jornal El Comercio noticiou pequenas manifestações que ocorreram em Quito, em frente à Embaixada do Brasil, com apenas 12 pessoas, em apoio ao governo e contra o impeachment da presidenta Dilma Rousseff ${ }^{25}$. Em outra reportagem, o mesmo jornal, enfatizou as tensões nas ruas e no parlamento brasileiro, durante o mês de abril, com a aproximação da votação do impeachment. A mesma reportagem afirmou que Dilma e Lula estariam em um momento de tudo ou nada na disputa pelo parlamento e pelas ruas $^{26}$. O El Comercio também publicou um artigo sobre a queda dos projetos socialistas na América do Sul do Século XXI. No caso brasileiro, o artigo argumenta que esse projeto está fracassando por culpa da má administração e da corrupção nos governos Lula e Dilma ${ }^{27}$. Além disso, o jornal divulgou um pronunciamento de Baltasar Garzón (ex-juiz espanhol que processou Augusto Pinochet) afirmando que Dilma e Lula são vítimas de um golpe institucional ${ }^{28}$.

O presidente do Equador, Rafael Correa, afirmou que a América do Sul está sendo ameaçada por tentativas de desestabilização dos governos progressistas da região e comparou o processo ao plano estadunidense de auxílio a golpes de Estado na América do Sul, contra governos de esquerda na Guerra Fria, tendo alguma responsabilidade na ascensão e manutenção de algumas ditaduras militares sulamericanas na época - o Plano Condor. Para Correa, o novo Plano Condor já não necessita de ditaduras militares, mas de juízes submissos e de uma imprensa corrupta. Correa também manifestou o seu apoio ao ex-presidente Lula, dizendo que o surgimento de acusações de supostos atos de corrupção não é apenas uma casualidade ${ }^{29}$.

${ }^{25}$ EL COMERCIO. Uma manifestación de apoyo a Dilma Rousseff em Quito. Disponível em: http://www.elcomercio.com/actualidad/manifestacion-apoyo-dilmaroussef-quito-brasil.html Acesso em: 25 de abr. de 2016

${ }^{26}$ EL COMERCIO. Dilma Rousseff y Lula da Silva, a todo o nada em el Parlamento y em las calles. Disponível em: http://www.elcomercio.com/actualidad/dilmarousseff-luladasilva-brasil-impeachment-

$\begin{array}{lllllll}\text { politica.html Acesso em: } 25 \text { de abr. de } 2016 & & & & & \\ 27 & \text { EL } & \text { COMERCIO. } & \text { El socilaismo del siglo XXI. Disponível em: }\end{array}$ http://www.elcomercio.com/cartas/socialismo-siglo-xxi-1.html Acesso em: 25 de abr. de 2016.

${ }^{28}$ EL COMERCIO. Baltasar Garzón dice que Rousseff y Lula son víctimas de 'um aquelarre'. Disponível em: http://www.elcomercio.com/actualidad/baltasargarzon-rousseff-lula-victimas-politica.html Acesso em: 26 de abr. de 2016.

29 AGÊNCIA BRASIL. Rafael Correa diz que América do Sul está sob ameaça de novo Plano Condor. Disponível em: http://agenciabrasil.ebc.com.br/internacional/noticia/2016-03/rafael-correa-diz-queamerica-do-sul-esta-sob-ameaca-de-novo-plano Acesso em: 25 de abr. de 2016. 


\section{Destaques da Agenda}

Primeiramente, temos cinco países, contando com o Brasil, que tiveram algum período ou mais de um período de governos militares e agora se encontram em momentos históricos de relativa estabilidade política e democrática. Para alguns desses países - principalmente o Chile, a Bolívia, e o Equador - o impeachment de Dilma Rousseff poderia acarretar numa onda de rupturas democráticas no continente, levando junto o enfraquecimento da esquerda sul-americana. Enfraquecimento esse que possui uma espécie de marco a eleição de Mauricio Macri na Argentina, o que pode ser entendido como o fim do Kirchnerismo.

Em segundo lugar, vemos como os líderes das nações selecionadas têm se colocado em pronunciamentos e entrevistas perante a crise política brasileira. Evo Morales vêm sendo o principal apoiador político de Dilma Rousseff dentre estes pesquisados, principalmente por afinidade ideológica e por sua forte amizade com o expresidente Lula da Silva, a quem ele costuma chamar de irmão mais velho. Rafael Correa, presidente do Equador, chegou a comparar o momento atual da América do Sul e da crise política brasileira com a Operação Condor, mas ao invés de militares os golpes são dados por imprensas corruptas e juízes submissos. Michelle Bachelet também se pronunciou em defesa de Dilma Rousseff, enfatizando suas qualidades pessoais, colocando-a como séria, honesta e responsável. Além de haver alguma afinidade política entre as duas líderes, o pronunciamento também derivou de uma sororidade entre elas, por serem as duas últimas líderes mulheres do continente. Há de se levar em conta a crise política da qual Bachelet está conseguindo se recuperar no ano de 2016, o que pode gerar alguma simpatia dela com Dilma por entender os desafios que a presidenta brasileira enfrenta.

Por outro lado, Ollanta Humala, presidente do Peru, não se pronunciou diretamente sobre o assunto, nem em apoio ou contra o impeachment. O distanciamento de Ollanta Humala é motivado pelas acusações contra a sua mulher, a primeira-dama Nadine Heredia. Além de outros membros do governo que também estão sendo investigados e por causa da suspeita de sua campanha ter recebido dinheiro ilícito de 
empresas brasileiras envolvidas na Lava Jato. Um pronunciamento contundente pró ou contra o impeachment seria arriscado para a situação de Ollanta.

Em terceiro lugar, é identificado que o momento mais dramático para a mídia desses quatro países foi o escalonamento dos atritos entre Dilma e o vice-presidente, Michel Temer. O episódio em que Dilma acusa o seu vice-presidente de traidor e de chefe da conspiração foi encarado pela maioria da mídia desses países como algo surpreendente, uma vez que são esperados o apoio e a harmonia na relação entre um vice-presidente e o presidente. Também foi encarado com suspeita o vazamento do áudio de Michel Temer, no qual ele apresenta suas visões para um futuro mandato. Esse vazamento foi retratado majoritariamente como proposital e como uma forma de campanha, pela mídia dos quatro países. Também foi bastante explorada na mídia a falta de acusações de enriquecimento ilícito contra a presidenta Dilma Rousseff, apesar das múltiplas acusações que pairam sobre membros da oposição e sobre membros do governo.

Ao analisarmos os posicionamentos dos jornais pesquisados vemos que ainda existe forte divergência no debate sobre as pedaladas fiscais, se elas podem ser consideradas como motivos para impeachment. Apesar disso foi visto um consenso sobre a corrupção generalizada no cenário político brasileiro, especialmente no legislativo. Na mídia dos quatro países pesquisados, inclusive na Bolívia, existe ainda a incerteza sobre a validade ou falta de validade das pedaladas fiscais como motivo para o impeachment. Também ainda há o debate se esse impeachment pode ser chamado de golpe ou não. Poucos jornais publicaram artigos de opinião que mostrassem discursos fortes sobre esses temas.

Finalmente, a percepção de que os três poderes são permeados por corrupção se mostrou consensual na mídia pesquisada. Principalmente, em relação ao poder legislativo, com algumas mídias enfatizando as vastas acusações de corrupção contra o presidente da Câmara, Eduardo Cunha. Alguns dos artigos aqui pesquisados entenderam as acusações que pendem contra boa parte do legislativo brasileiro como algo que deslegitima o processo de impeachment. 


\section{Reflexões Finais}

A partir do que foi visto nos jornais selecionados, algumas projeções podem ser feitas, por meio dessa análise, que abrangem o futuro da esquerda na América do Sul, a estabilidade institucional do continente e a posição do Brasil como ponta de lança dos países sul-americanos e como potência global. Podemos ver o evidente abalo sofrido pela esquerda nos países pesquisados. Abalo esse que tende a aumentar caso o impeachment da presidenta Dilma Rousseff seja efetivo. Por outro lado, esse cenário pode criar também um sentido de emergência e de união nos movimentos e frentes da esquerda latino-americanas podendo acarretar numa polarização maior das posições políticas por todo o continente. Vale dizer que o receio da volta de regimes não democráticos ainda é forte nos países pesquisados, esse receio pode gerar cautela dos agentes políticos perante qualquer situação de instabilidade.

As notícias e os artigos observados aqui sugerem que um eventual governo Michel Temer poderia ser bem recebido por países como o Peru, principalmente se for mantida uma agenda de integração regional na América do Sul. Caso uma administração Temer tenha sucesso em enfraquecer a crise econômica também seria bom para o continente, mesmo que a maioria dos países componentes não esteja enfrentando crise parecida. Apesar disso, uma melhora no curto prazo da situação econômica brasileira parece ser improvável. Chile, Bolívia e Equador podem vir a romper certas ligações construídas com o Brasil durante o período Lula-Dilma, principalmente por desconfiança e falta de afinidade política com Michel Temer, talvez não o reconhecendo como presidente legítimo. A visão de política externa de Michel Temer para a América do Sul ainda não estava clara durante o mês de abril, isso dificultou prognósticos sobre as possibilidades de continuação ou rompimento com o cenário atual. 


\section{Bibliografia}

EL COMERCIO. Nadine: No recibí "coimas ni sobornos de empresas brasileñas. Disponível em: http://elcomercio.pe/politica/congreso/nadine-heredia-ira-hoy-comision-lava-jato-confirmaroy-gates-noticia-1890724 Acesso em: 25 de abr. de 2016.

LA NACION. Bachelet: Dilma Rousseff es uma 'mujer honesta y responsable. Disponível em: http://www.lanacion.cl/noticias/pais/politica/bachelet-dilma-rousseff-es-una-mujer-honestay-responsable/2016-04-06/165342.html Acesso em: 25 de abr. de 2016.

LA NACION. Defensores de Dilma Rousseff salen em la calle. Disponível em: http://www.lanacion.cl/noticias/videos/mundo/defensores-de-dilma-rousseff-salen-a-lacalle/2016-04-01/105530.html Acesso em: 25 de abr. de 2016.

24 HORAS. De qué acusan exactamente a Dilma Rousseff em el Congreso brasileño (y no es corrupción). Disponível em: http://www.24horas.cl/noticiasbbc/de-que-acusan-exactamentea-dilma-rousseff-en-el-congreso-brasileno-y-no-es-corrupcion-1984456 Acesso em: 25 de abr. de 2016.

24 HORAS. Quién es Michel Temer, el hombre que se está preparando para sustituir a Dilma Rousseff em la presidencia de Brasil. Disponível em: http://www.24horas.cl/noticiasbbc/quien-es-michel-temer-el-hombre-que-se-esta-preparandopara-sustituir-a-dilma-rousseff-en-la-presidencia-de-brasil-1986092 Acesso em: 25 de abr. de 2016.

LA NACION. Vicepresidente Temer divulga por error su discurso em caso de sustituir a

Rousseff. Disponível em: http://www.lanacion.cl/noticias/mundo/brasil/vicepresidente-temerdivulga-por-error-su-discurso-en-caso-de-sustituir/2016-04-11/183551.html Acesso em: 25 de abr. de 2016.

LA TERCERA. Evo Morales pide cumbre de Unasur em Brasil para defender a Dilma y Lula. Disponível em: http://www.latercera.com/noticia/mundo/2016/03/678-672974-9-evomorales-pide-cumbre-de-unasur-en-brasil-para-defender-a-dilma-y-lula.shtml Acesso em: 25 de abr. de 2016. 
EL COMERCIO. Uma manifestación de apoyo a Dilma Rousseff em Quito. Disponível em: http://www.elcomercio.com/actualidad/manifestacion-apoyo-dilmaroussef-quito-brasil.html Acesso em: 25 de abr. de 2016

EL COMERCIO. Dilma Rousseff y Lula da Silva, a todo o nada em el Parlamento y em las calles. Disponível em: http://www.elcomercio.com/actualidad/dilmarousseff-luladasilva-brasilimpeachment-politica.html Acesso em: 25 de abr. de 2016

EL COMERCIO. EI socilaismo del siglo XXI. Disponível em: http://www.elcomercio.com/cartas/socialismo-siglo-xxi-1.html Acesso em: 25 de abr. de 2016.

EL UNIVERSO. Debate sobre el supuesto 'golpe' contra Rousseff. Disponível em: http://www.eluniverso.com/noticias/2016/04/01/nota/5496201/debate-sobre-supuesto-golpecontra-rousseff_Acesso em: 25 de abr. de 2016.

EL TIEMPO. 'Hay razones jurídicas para hacer um juicio politico contra Rousseff'. Disponível em: http://www.eltiempo.com/mundo/latinoamerica/dilma-rousseff-juicio-politicoen-brasil/16561447 Acesso em: 25 de abr. de 2016.

EL TIEMPO. Dilma Rousseff acusa a su vicepresidente de 'traidor'. Disponível em: http://www.eltiempo.com/mundo/latinoamerica/declaraciones-de-dilma-de-micheltemer/16562085 Acesso em: 25 de abr. de 2016.

EL ESPECTADOR. Así marcharon miles de brasileños en apoyo a Dilma Rousseff. Disponível em: http://www.elespectador.com/noticias/elmundo/asi-marcharon-miles-debrasilenos-apoyo-dilma-rousseff-video-624894 Acesso em: 25 de abr. de 2016.

EL ESPECTADOR. Dilma. Disponível em: http://www.elespectador.com/opinion/dilma-0 Acesso em: 25 de abr. de 2016.

EL ESPECTADOR. Brasil: Quién está libre de culpas? Disponível em: http://www.elespectador.com/noticias/elmundo/brasil-quien-esta-libre-de-culpas-articulo627299 Acesso em: 25 de abr. de 2016.

AGÊNCIA BRASIL. Rafael Correa diz que América do Sul está sob ameaça de novo Plano Condor. Disponível em: http://agenciabrasil.ebc.com.br/internacional/noticia/2016-03/rafaelcorrea-diz-que-america-do-sul-esta-sob-ameaca-de-novo-plano Acesso em: 25 de abr. de 2016. 
DIARIO CORREO. Dilma Rousseff y um "golpe moderno". Disponível em: http://diariocorreo.pe/mundo/dilma-rousseff-y-un-golpe-moderno-667929/Acesso em: 25 de abr. de 2016.

DIARIO CORREO. Dilma Rousseff afirma que proceso em su contra tiene "compnente fuerte" de machismo. Disponível em: http://diariocorreo.pe/mundo/dilma-rousseff-dice-queproceso-en-su-contra-tiene-componente-fuerte-de-machismo-667368/. Acesso em: 25 de abr. de 2016.

DIARIO CORREO. Dilma Rousseff sobre votación del 'impeachment': Me siento indignada”. Disponível em: http://diariocorreo.pe/mundo/dilma-rousseff-sobre-votaciondel-impeachment-me-siento-indignada-667181/Acesso em: 25 de abr. de 2016.

DIARIO CORREO. Brasil: diputados aprobaron impeachment contra Dilma Rousseff. Disponível em: http://diariocorreo.pe/mundo/brasil-diputados-aprobaron-impeachment-contradilma-rousseff-667039/ Acesso em: 25 de abr. de 2016.

24 HORAS. En contraste: Así se vivió em Brasil el revés de Rousseff em la Cámara de diputados. Disponível em: http://www.24horas.cl/internacional/en-contraste-asi-se-vivio-enbrasil-el-reves-de-rousseff-en-la-camara-de-diputados-1989722 Acesso em: 25 de abr. de 2016

24 HORAS. Rousseff considera que está siendo víctima de um trato injusto em parte por ser mujer. Disponível em: http://www.24horas.cl/internacional/rousseff-considera-que-estasiendo-victima-de-un-trato-injusto-en-parte-por-ser-mujer-1991218_Acesso em: 19 de abr. de 2016.

24 HORAS. Dilma Rousseff tras aprobación de impeachment: "Es um golpe de Estado no tradicional". Disponível em: http://www.24horas.cl/internacional/dilma-rousseff-trasaprobacion-de-impeachment-es-un-golpe-de-estado-no-tradicional-1990347 Acesso em: 25 de abr. de 2016.

LA NACION. 'Em nombre de dios y del pueblo brasilño' inicia a sesión que decide impeachment contra Rousseff. Disponível em: http://www.lanacion.cl/noticias/mundo/brasil/en-nombre-de-dios-y-del-pueblo-brasileno-iniciasesion-que-decide/2016-04-17/163633.html Acesso em: 25 de abr. de 2016. 
LA NACION. Brasil: piden sancionar al polémico diputado fan de um torturador. Disponível em: http://www.lanacion.cl/noticias/videos/mundo/brasil-piden-sancionar-alpolemico-diputado-fan-de-un-torturador/2016-04-21/120238.html Acesso em: 25 de abr. de 2016.

LA NACION. Nuevo testimonio confirma sobornos a timonel de la cámara de diputados em Brasil. Disponível em: http://www.lanacion.cl/noticias/mundo/brasil/nuevo-testimonioconfirma-sobornos-a-timonel-de-la-camara-de-diputados/2016-04-26/211136.html Acesso em: 30 de abr. de 2016.

LA NACION. Rousseff se dice 'triste' pero dispuesta a defender su mandato de 'um golpe'. Disponível em: http:/www.lanacion.cl/noticias/rousseff-se-dice-triste-pero-dispuesta-adefender-su-mandato-de-un/2016-04-18/203936.html Acesso em: 25 de abr. de 2016.

EL TIEMPO. Dilma y la debacle de uma promesa. Disponível em: http://www.eltiempo.com/mundo/latinoamerica/crisis-politica-en-brasil/16575546 Acesso em: 30 de abr. de 2016.

EL TIEMPO. La conspiración contra Dilma. Disponível em: http:/www.eltiempo.com/opinion/columnistas/la-conspiracion-contra-dilma-sergio-munozbata-columna-el-tiempo/16573038 Acesso em: 26 de abr. de 2016.

EL TIEMPO. Golpe en Brasil. Disponível em: http://www.eltiempo.com/opinion/columnistas/golpe-en-brasil-julio-gomes-dos-santoscolumnista-el-tiempo/16571524_Acesso em: 25 de abr. de 2016.

EL TIEMPO. Editorial: La sinsalida brasileña. Disponível em: http://www.eltiempo.com/mundo/latinoamerica/la-sinsalida-brasilena-editorial-el-tiempo-20-deabril-de-2016/16568531 Acesso em: 25 de abr. de 2016.

EL ESPECTADOR. Brasi, de la fama al olvido. Disponível em: http://www.elespectador.com/opinion/brasil-de-fama-al-olvido Acesso em: 25 de abr. de 2016.

EL ESPECTADOR. Dilma Rousseff y la situación en Brasil: cuál democracia? Disponível em: $\quad$ http://www.elespectador.com/noticias/elmundo/dilma-rousseff-y-situacion-brasil-cualdemocracia-articulo-627763 Acesso em: 25 de abr. de 2016. 
EL ESPECTADOR. Brasil, em el limbo. Disponível em: http://www.elespectador.com/opinion/editorial/brasil-el-limbo-articulo-627994_Acesso em: 25 de abr. de 2016.

EL COMERCIO. Baltasar Garzón dice que Rousseff y Lula son víctimas de 'um aquelarre'. Disponível em: http://www.elcomercio.com/actualidad/baltasargarzon-roussefflula-victimas-politica.html_Acesso em: 26 de abr. de 2016.

El COMERCIO. Dilma Rousseff a Nueva York, em campaña contra el 'golpe' em Brasil. Disponível em: http://www.elcomercio.com/actualidad/dilmarousseff-nuevayork-campanabrasil-juiciopolitico.html_Acesso em: 25 de abr. de 2016.

EL COMERCIO. Lula y su partido quedan al borde del abismo junto com Rousseff. Disponível em: http://www.elcomercio.com/actualidad/brasil-dilam-lula-abismojuiciopolitico.html_Acesso em: 25 de abr. de 2016. 